\title{
Susceptibility of the Elderly to SARS-CoV-2 Infection: ACE-2 Overexpression, Shedding, and Antibody- dependent Enhancement (ADE)
}

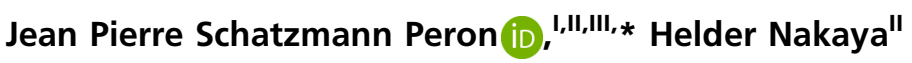 \\ 'Laboratorio de Interacoes Neuroimunes, Departamento de Imunologia - ICB IV, Universidade de Sao Paulo (USP), Sao Paulo, SP, BR. "Plataforma Cientifica \\ Pasteur-USP, Universidade de Sao Paulo (USP), Sao Paulo, SP, BR. "'Programa de Pos Graduacao em Alergia e Imunopatologia, Faculdade de Medicina \\ FMUSP, Universidade de Sao Paulo, Sao Paulo, SP, BR.
}

Peron JPS, Nakaya H. Susceptibility of the Elderly to SARS-CoV-2 Infection: ACE-2 Overexpression, Shedding, and Antibody-dependent Enhancement (ADE). Clinics. 2020;75:e1912

*Corresponding author. E-mail: jeanpierre@usp.br

The world is currently facing a serious SARS-CoV-2 infection pandemic. This virus is a new isolate of coronavirus, and the current infection crisis has surpassed the SARS and MERS epidemics that occurred in 2002 and 2013, respectively. SARS-CoV-2 has currently infected more than 142,000 people, causing 5,000 deaths and spreading across more than 130 countries worldwide. The spreading capacity of the virus clearly demonstrates the potential threat of respiratory viruses to human health, thereby reiterating to the governments around the world that preventive health policies and scientific research are pivotal to overcoming the crisis. Coronavirus disease (COVID-19) causes flu-like symptoms in most cases. However, approximately $15 \%$ of the patients need hospitalization, and $5 \%$ require assisted ventilation, depending on the cohorts studied. What is intriguing, however, is the higher susceptibility of the elderly, especially individuals who are older than 60 years of age, and have comorbidities, including hypertension, diabetes, and heart disease. In fact, the death rate in this group may be up to $10-12 \%$. Interestingly, children are somehow less susceptible and are not considered as a risk group.

Therefore, in this review, we discuss some possible molecular and cellular mechanisms by virtue of which the elderly subjects may be more susceptible to severe COVID-19. Toward this, we raise two main points, i) increased ACE-2 expression in pulmonary and heart tissues in users of chronic angiotensin 1 receptor (AT1R) blockers; and ii) antibody-dependent enhancement (ADE) after previous exposure to other circulating coronaviruses. We believe that these points are pivotal for a better understanding of the pathogenesis of severe COVID-19, and must be carefully addressed by physicians and scientists in the field.

KEYWORDS: SARS-CoV-2; Immunopathology; ACE-2.

\section{INTRODUCTION}

The world is facing a major public health crisis due to the pandemic caused by a recently-described coronavirus, named SARS-CoV-2 (1-3). Reaching proportions that far surpass those of SARS and MERS, the SARS-CoV-2 epidemic started in Wuhan, China in December 2019, but has now spread to more than 130 countries worldwide and has infected approximately 142,000 people, with more than 5,000 deaths being attributed to it (WHO, March $\left.13^{\text {th }} 2020\right)(4)$. Sequencing analysis of the viral genome has revealed mutations in the spike protein-which is essential for SARS-CoV-2 attachment and invasion into host cells-may have favored the spill over from bats to humans (1). Most patients infected

Copyright $\odot 2020$ CLINICS - This is an Open Access article distributed under the terms of the Creative Commons License (http://creativecommons.org/licenses/by/ 4.0/) which permits unrestricted use, distribution, and reproduction in any medium or format, provided the original work is properly cited.

No potential conflict of interest was reported.

Received for publication on April 8, 2020. Accepted for publication on April 15, 2020

DOI: 10.6061/clinics/2020/e1912 with coronaviruses develop a mild flu-like disease, in which the most common symptoms are fever and cough. However, in a study of 1,099 patients from 552 hospitals from 30 provinces of China in 2020, Guan W et al. (5), revealed that $15.7 \%$ of the patients who develop severe disease have increased difficulty in breathing because of pneumonia. Radiological imaging of the lungs revealed opacity in $56.4 \%$ of the patients. Approximately $2.7 \%$ of the patients needed assisted ventilation, and $1.4 \%$ died (1).

However, coronavirus disease (COVID-19) may rapidly develop into severe acute respiratory syndrome (SARS) in elderly subjects ( $>60 \mathrm{yr}$ ), especially in those with comorbidities, such as hypertension, diabetes, and pulmonary diseases $(1,4,6)$. What is intriguing is that, unlike in the case of influenza (7), children are not included in the risk group, as very few cases of severe COVID-19 in children have been reported, and there have been no reports of death in children under the age of 9. This raises questions regarding the cellular and molecular mechanisms associated with the severity of COVID-19. Understanding and elucidating such mechanisms may greatly improve our knowledge of the pathogenesis of the disease, and thus guide health professionals as to how to better treat the elderly population. 
Toward this, we raise two main points of discussion, i) the increased angiotensin-converting enzyme-2 (ACE-2) expression in pulmonary and heart tissues of hypertensive patients with chronic use of AT1R blockers and ii) antibody-dependent enhancement (ADE) after previous exposure to other circulating coronaviruses.

\section{SARS-CoV-2 and ACE-2}

After entering the host-usually through aerosolized viral particles or contact with contaminated surfaces-the virus needs to undergo its biological cycle. Spike proteins-that are coded by the $\mathrm{S}$ gene in one of the open reading frames of the viral genome-need to interact with viral receptors on the surface of host cells. SARS-CoV-2 spike proteins bind to angiotensin-converting enzyme-2 (ACE-2), which is expressed in the epithelial cells of the lungs $(8,9)$. This is the main reason why coronaviruses often cause respiratory disease. Notably, ACE-2 may also be highly expressed in intestinal tissues (9), leading to diarrhea, as observed in $60 \%$ of the patients during the SARS-CoV epidemic in 2002. Only a few patients with SARS-CoV-2 infection had diarrhea, although viral particles may be detected in the stool (10). After attaching to the ACE-2 through the receptor-binding domain (RBD) of the S1 and S2 domains of the spike protein, the viral envelope fuses with the host cell membrane and is further internalized. Genetic material, a positive RNA strand of approximately $20-32 \mathrm{~kb}$, is released into the cytoplasm for replication (1). Thus, the importance of ACE-2 expression dynamics for viral infectivity, tropism, and pathogenicity is evident.

ACE-2, or ACE-related carboxypeptidase, is an 805 amino acid transmembrane protein which is an important member of the renin-angiotensin system that plays a pivotal role in the regulation of blood pressure (11). ACE converts angiotensin I (Ang I) into angiotensin II (Ang II), whereas ACE-2 converts Ang II into angiotensin 1-7 (Ang 1-7) or angiotensin 1-9 (Ang 1-9) (12). Ang II and Ang 1-7 have antagonizing effects, as Ang II binds to angiotensin 1 receptor (AT1R), inducing vasoconstriction and increase in blood pressure, whereas Ang 1-7 binds to AT2R, leading to vasodilatation and decrease in blood pressure $(11,12)$.

As the renin-angiotensin system affects blood pressure and kidney function, ACE inhibitors and AT1R blockers are widely used in hypertensive and cardiac patients (13). In this context, the chronic use of ACE inhibitors or AT1R antagonists may be of particular relevance for patients infected with SARS-CoV-2, as they may alter the dynamics of ACE-2 expression and thus increase susceptibility to SARS-CoV-2 infection.

It has already been demonstrated by using hypertensive rat models that AT1R blockade elevates ACE-2 expression. Treatment with losartan and lisinopril, either alone or in combination, significantly increases ACE-2 mRNA in cardiomyocytes of rats. This is associated with higher Ang 1-7 plasma concentrations (14). This was corroborated by analyzing the heart tissue from rats with myocardial infarction that were treated with losartan (15). Concordantly, olmesartan, a more effective AT1R antagonist, significantly increased both cardiac and renal expression of ACE-2 in Wistar-Kyoto rats (16). This is in agreement with the use of perindopril, an ACE inhibitor, in rats (17).

Another interesting feature of the dynamics of ACE-2 expression in tissues is its ability to be cleaved from the cell surface by a metalloproteinase called ADAM17 (TACE) (18). The ACE-2 ectodomain gets cleaved, releasing soluble ACE-2 (sACE-2), whose role has not been fully elucidated. However, it has been shown that a higher concentration of SACE2 in the plasma correlates with a poorer prognosis after heart failure (19). Notably, sACE-2 may also be detected at higher concentrations in the cerebrospinal fluid in hypertensive patients. This has been corroborated in $\mathrm{Nefh}^{\text {cre }} \mathrm{x} \mathrm{AT}_{\mathrm{a}} \mathrm{R}^{\text {flox/flox }}$ mice, indicating that ACE-2 and sACE-2 levels in the brain are associated with the etiology of neurogenic hypertension (20).

Further, it was demonstrated that ACE-2 may be cleaved by other mechanisms. For instance, the SARS spike protein may modulate ADAM17 expression, which in turn cleaves ACE-2 into its soluble form. This was found to be dependent on the cytoplasmic domain of ACE-2, as siRNA against ADAM17 or ACE-2 lacking intracellular domains abrogated this phenomenon (21). Interestingly, increased shedding of ACE-2 correlates with worsening of the disease, probably because of an increase in Ang II instead of Ang 1-7. This leads to increased vascular permeability and local inflammation. Interestingly, ACE-2 cleavage from the cell surface may also occur in lung epithelial cells (22). Thus, cleavage of ACE-2 into sACE-2 would compromise the effect of Ang 1-7 on AT2R, thereby reducing pulmonary hypertension and inflammation.

Altogether, as depicted in Figure 1, these data show that modulating the renin-angiotensin axis alters ACE-2 expression in several tissues, especially in the lung and heart tissues. The use of ACE inhibitors and AT1R antagonists seems to upregulate ACE-2 expression, facilitating viral attachment and entry. The further presence of the virus itself or some cytokines, including TNF- $\alpha$, leads to ACE- 2 release from the cell membrane, abrogating its function to counteract Ang II.

Altogether, ACE-2 overexpression may facilitate viral replication in lung tissue and promote lung vascular permeability, a common feature of severe SARS-CoV-2 infection. In summary, this may greatly impact the outcome of SARSCoV-2 infection in elderly and hypertensive patients, as ACE-2 is the putative attachment and invasion receptor for coronaviruses $(8,23)$. In fact, the use of TACE inhibitors as SARS antiviral agents has already been proposed in experimental models $(2,3,24)$.

\section{aNTIBODY-DEPENDENT ENHANCEMENT}

ADE is a phenomenon by which viruses use preexisting non-neutralizing antibodies from previous exposure to invade host cells through Fc receptor-mediated internalization. This is most commonly observed during secondary dengue virus (DENV) infection, causing severe hemorrhagic disease (25). Notably, the possibility of ADE between Zika virus (ZIKV), the causative agent of ZIKV congenital syndrome (26), and DENV has been intensely debated recently (27-29). Moreover, ADE has been the focus of debate for Ebola (30) and HIV (31) infections.

During ADE, preexisting antibodies elicited during a previous viral exposure are not able to neutralize viral particles during a secondary infection with any antigenicrelated virus. Instead, IgG-opsonized viral particles then target $\mathrm{F} c \gamma \mathrm{R}$ expressed on endothelial and immune cells, facilitating viral internalization into host cells. Further, after intense viral replication, endothelial cells may respond 


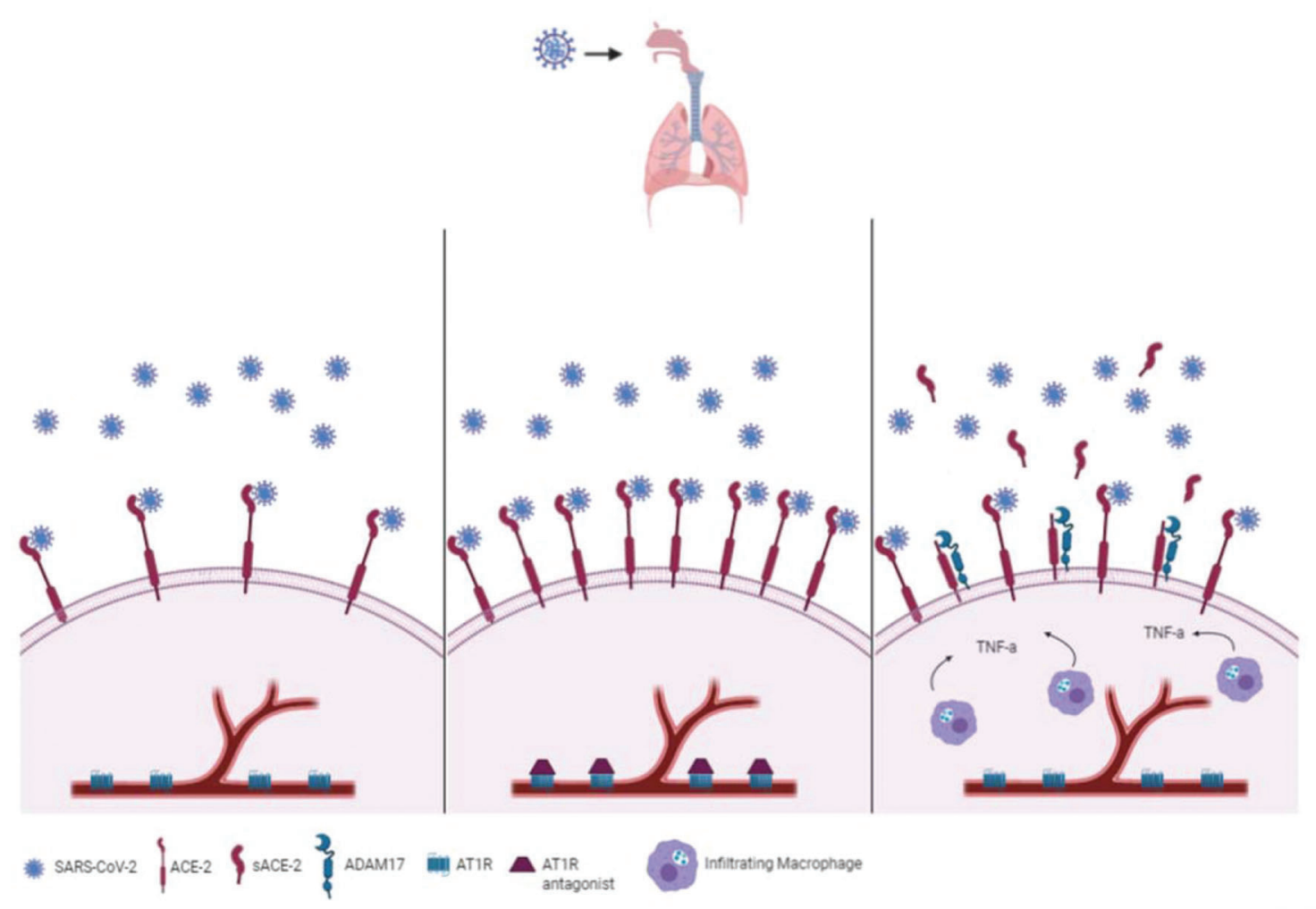

Figure 1 - Illustrative scheme of ACE-2 expression in the lungs. Left panel: Normally expressed ACE-2 in the lung tissue interacts with SARS-CoV-2. Middle panel: Increased expression of ACE-2 in lung tissues of hypertensive patients under chronic treatment with AT1R blockers. Right panel: ADAM17 cleaves ACE-2, releasing its soluble form, sACE-2, whose levels are increased in the presence of TNF- $\alpha$. Illustration was developed by the authors using www.biorender.com.

by increasing vascular permeability and allowing exudate extravasation and bleeding. However, monocytes become highly activated and may initiate a cytokine storm (32).

In the context of SARS-CoV-2, it is plausible to think that ADE occurs. As mentioned in the introduction section, elderly ( $>60 \mathrm{yr}$ ) patients are more susceptible to infection for unknown reasons. As coronaviruses in general are highly prevalent in the global population, causing mild infection and flu-like symptoms, seroconversion into previous circulating coronaviruses is probably widespread. Thus, it is reasonable to infer that elderly patients, for obvious reasons, have been exposed to previous infections more times than younger subjects. This would imply a vaster repertoire of antibodies against coronavirus epitopes produced by longliving plasma cells, which in fact has recently been shown to expand during SARS-CoV-2 infection.

However, whether these antibodies are either neutralizers or enhancers must be further addressed. It is worth mentioning that, concerning the new SARS-CoV-2, sequencing analysis of the viral genome isolated in Wuhan, China indicated that mutations mainly occurred within the coding sequence of the spike protein, which has less than $40 \%$ sequence identity with that of previously circulated coronaviruses (1). These mutations may be responsible not only for the spill over from bats to humans, but also for inducing $\mathrm{ADE}$, as changes in spike epitopes may result in interactions with non-neutralizing antibodies. Corroborating this, a novel epitope, which was lacking in previous isolates, was mapped (33).
As COVID-19 is not a hemorrhagic disease, it is probable that ADE, if present, is not mediated by endothelial cells. However, it has already been shown that lung epithelial cells express high levels of Fc $\gamma$ RIIa (34). Moreover, immune cells, including monocytes and dendritic cells, highly express this receptor. These populations, especially monocytes, greatly account for the inflammatory infiltrate in the lungs during pneumonia, which is consistent with the transient lymphopenia observed in patients as circulating cells may migrate to the lungs. Conversely, lung imaging of patients with severe COVID-19 shows a great degree of lung opacity, which is consistent with edema and cellular infiltrate (5). Thus, it is feasible that lung-infiltrating monocytes expressing Fc $\gamma$ R greatly favor SARS-CoV-2 replication in the lung tissue, accounting for the greater susceptibility of the elderly patients.

Corroborating this hypothesis, young individuals and children do not represent the risk group for severe disease, which greatly differs from the case of influenza (7), for instance. In the context of ADE, it is plausible to think that children-as they had less or no exposure to previous circulating coronaviruses-carry a very restricted repertoire of IgG-or only low-affinity IgM-which is not capable of inducing ADE. In this context, mapping complementarity determining regions (CDRs) in IgGs from young and elderly individuals would be of great importance not only to find neutralizing antibodies but also to address this hypothesis.

Additionally, previous studies on MERS and SARS have already highlighted the possibility of ADE. A recent report published by Wan $\mathrm{Y}$ et al. elucidated the mechanism by 


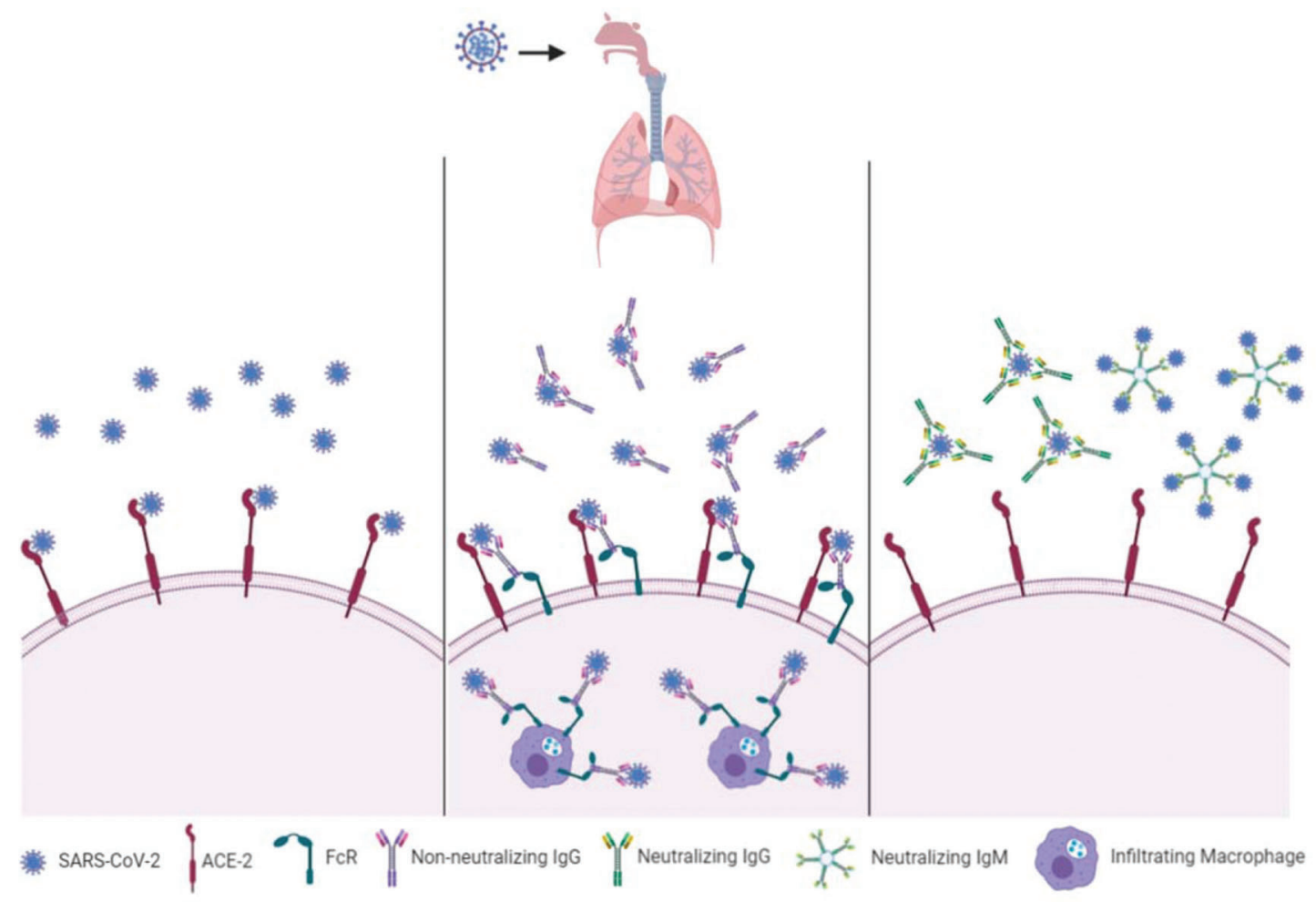

Figure 2 - Illustrative scheme of ADE during SARS-CoV-2 infection. Left panel: First infection and lack of preexisting antibodies allow viral particles to interact with ACE-2. Middle panel: Preexisting low-affinity antibodies or antibodies at sub-optimal concentrations bind to viral particles and facilitate the viral internalization mediated by FcRs expressed on either the epithelial or immune cells. Right panel: Neutralizing IgGs elicited in response to vaccination, or neutralizing lgM that do not mediate enhancement bind to viral particles. Illustration created by the authors using www.biorender.com.

which monoclonal antibodies (mAbs) induce ADE in human cells. Interestingly, mAbs that target the RBD of SARS and MERS spike proteins induced conformational changes in the protein that favors an interaction with dipeptidyl peptidase 4 (DPP4), the receptor for MERS (38). Moreover, immunocomplexes also promoted viral entry. However, increasing concentrations of antibodies block viral invasion, as RBDs become inaccessible.

This is consistent with previous findings by Wang $Q$ et al. (39) who infected the promonocytic cell line HL-CZ-that expresses both ACE-2 and Fc $\gamma \mathrm{R}$-with SARS-CoV-2 in the presence of increasing concentrations of anti-sera. Their data demonstrated that high concentrations of antibodies neutralized the virus, whereas lower concentrations induced ADE. More interestingly, the anti-sera also recognized spike protein-related antigens.

Another study on SARS-CoV-2 using Rhesus monkeys showed that immunization with full-length SPIKE glycoprotein led to increased disease severity, mostly to because of an increase in neutralizing antibodies (NAb) (35). The study demonstrated that NAbs switched the phenotype of lunginfiltrating macrophages to a pro-inflammatory M1 profile, instead of the tissue-healing profile M2. This aggravated lung injury and greatly contributed to its pathology. Conversely, previous studies using samples from deceased patients suffering from SARS-CoV infection indicated that $\mathrm{NAb}$ titers reached higher levels earlier in these patients, compared to that in patients who survived (36). This may indicate that ADE and the role of preexisting antibodies are in fact very relevant to the overall outcome of the infection.
Thus, as indicated in Figure 2, circulating antibodies, instead of neutralizing the current circulating SARS-CoV-2, may bind to viral particles and thus promote Fc-mediated internalization by lung epithelial cells and infiltrating monocytes, contributing to the worsening of COVID-19. These are the most recent and mechanistic studies on ADE of coronaviruses thus far. Although the data are consistent, whether the phenomenon of ADE is observed in patients with severe COVID-19 is yet to be determined. Noteworthy, however, is the fact that immune complexes of low-avidity antibodies at sub-optimal concentrations were also responsible for the worsening of the pulmonary disease caused by H1N1 during the 2009 epidemic (37).

\section{CONCLUSIONS}

SARS-CoV-2 is the newest threat to human health and needs emergency action from governments and public health agencies worldwide, especially because of its pandemic potential as recently declared by the World Health Organization (WHO). In this context, it is essential to rapidly and deeply address all the possibilities concerning the severity of infection, especially in the elderly population that accounts for approximately $10-12 \%$ of the mortality rate. Here, we present several relevant aspects that may contribute to the increased susceptibility of the aforementioned population to COVID-19. We believe that i) increased expression of ACE-2 in hypertensive patients being treated with ACE inhibitors and AT1R blockers and ii) previous exposure to circulating coronaviruses with low neutralizing capacity to SARS-CoV-2 
may greatly contribute to the increased susceptibility of the elderly patients to COVID-19. To determine whether these hypotheses are correct, further investigations are needed, not only to better understand the etiology of the current SARS-CoV-2 infection, but also to be better prepared for future epidemics.

\section{ACKNOWLEDGMENTS}

JPSP is funded by FAPESP (grant numbers: \#2017/26170-0 and 2017/ 22504-1) and CNPq (301287/2016-3). HN is funded by FAPESP (grant numbers: \#2017/50137-3, 2012/19278-6, 2018/14933-2, 2018/21934-5, and 2013/08216-2) and CNPq (313662/2017-7).

\section{AUTHOR CONTRIBUTIONS}

Peron JPS conceived and wrote the manuscript. Nakaya $\mathrm{H}$ helped editing the manuscript.

\section{REFERENCES}

1. Zhou P, Yang XL, Wang XG, Hu B, Zhang L, Zhang W, et al. A pneumonia outbreak associated with a new coronavirus of probable bat origin. Nature. 2020;579(7798):270-3. https:/ / doi.org/10.1038/s41586-020-2012-7

2. Wu F, Zhao S, Yu B, Chen YM, Wang W, Song ZG, et al. A new coronavirus associated with human respiratory disease in China. Nature. 2020;579(7798):265-9. https://doi.org/10.1038/s41586-020-2008-3

3. Lu R, Zhao X, Li J, Niu P, Yang B, Wu H, et al. Genomic characterisation and epidemiology of 2019 novel coronavirus: implications for virus origins and receptor binding. Lancet. 2020;395(10224):565-74. https://doi. org/10.1016/S0140-6736(20)30251-8

4. WHO. World Health Organization - Situation Reports. Available from: https://www.who.int/docs/default-source/coronaviruse/situation-reports/ 20200315-sitrep-55-covid-19.pdf?sfvrsn=33daa5cb_6. 2020

5. Guan WJ, Ni ZY, Hu Y, Liang WH, Ou CQ, He JX, et al. Clinical Characteristics of Coronavirus Disease 2019 in China. N Engl J Med. 2020. https:/ / doi.org/10.1056/NEJMoa2002032

6. Wu C, Chen X, Cai Y, Xia J, Zhou X, Xu S, et al. Risk Factors Associated With Acute Respiratory Distress Syndrome and Death in Patients With Coronavirus Disease 2019 Pneumonia in Wuhan, China. JAMA Intern Med. 2020. https://doi.org/10.1001/jamainternmed.2020.0994

7. Wang $\mathrm{X}, \mathrm{Li}$ Y, O'Brien KL, Madhi SA, Widdowson MA, Byass $\mathrm{P}$, et al. Global burden of respiratory infections associated with seasonal influenza in children under 5 years in 2018: a systematic review and modelling study. Lancet Glob Health. 2020;8(4):e497-e510. https://doi.org/10.1016/ S2214-109X(19)30545-5

8. Li W, Moore MJ, Vasilieva N, Sui J, Wong SK, Berne MA, et al. Angiotensin-converting enzyme 2 is a functional receptor for the SARS coronavirus. Nature. 2003;426(6965):450-4. https://doi.org/10.1038/nature 02145

9. Hamming I, Timens W, Bulthuis ML, Lely AT, Navis G, van Goor H. Tissue distribution of ACE2 protein, the functional receptor for SARS coronavirus. A first step in understanding SARS pathogenesis. J Pathol. 2004;203(2):631-7. https://doi.org/10.1002/path.1570

10. Young BE, Ong SWX, Kalimuddin S, Low JG, Tan SY, Loh J, et al. Epidemiologic Features and Clinical Course of Patients Infected With SARS-CoV-2 in Singapore. JAMA. 2020. https://doi.org/10.1001/jama. 2020.3204

11. Crackower MA, Sarao R, Oudit GY, Yagil C, Kozieradzki I, Scanga SE, et al. Angiotensin-converting enzyme 2 is an essential regulator of heart function. Nature. 2002;417(6891):822-8. https://doi.org/10.1038/nature00786

12. Jiang F, Yang J, Zhang Y, Dong M, Wang S, Zhang Q, et al. Angiotensinconverting enzyme 2 and angiotensin 1-7: novel therapeutic targets. Nat Rev Cardiol. 2014;11(7):413-26. https://doi.org/10.1038/nrcardio.2014.59

13. Johansen ME, Yun J, Griggs JM, Jackson EA, Richardson CR. AntiHypertensive Medication Combinations in the United States. I Am Board Fam Med. 2020;33(1):143-6. https://doi.org/10.3122/jabfm.2020.01.190134

14. Ferrario CM, Jessup J, Chappell MC, Averill DB, Brosnihan KB, Tallant EA, et al. Effect of angiotensin-converting enzyme inhibition and angiotensin II receptor blockers on cardiac angiotensin-converting enzyme 2. Circulation. 2005;111(20):2605-10. https://doi.org/10.1161/CIRCULATION AHA.104.510461

15. Ishiyama Y, Gallagher PE, Averill DB, Tallant EA, Brosnihan KB, Ferrario $\mathrm{CM}$. Upregulation of angiotensin-converting enzyme 2 after myocardial infarction by blockade of angiotensin II receptors. Hypertension. 2004; 43(5):970-6. https://doi.org/10.1161/01.HYP.0000124667.34652.1a

16. Agata I, Ura N, Yoshida H, Shinshi $Y$, Sasaki H, Hyakkoku M, et al. Olmesartan is an angiotensin II receptor blocker with an inhibitory effect on angiotensin-converting enzyme. Hypertens Res. 2006;29(11):865-74 https://doi.org/10.1291/hypres.29.865

17. Huang ML, Li X, Meng Y, Xiao B, Ma Q, Ying SS, et al. Upregulation of angiotensin-converting enzyme (ACE) 2 in hepatic fibrosis by ACE inhibitors. Clin Exp Pharmacol Physiol. 2010;37(1):e1-6. https://doi.org/ 10.1111/j.1440-1681.2009.05302.x

18. Lambert DW, Yarski M, Warner FJ, Thornhill P, Parkin ET, Smith AI, et al Tumor necrosis factor-alpha convertase (ADAM17) mediates regulated ectodomain shedding of the severe-acute respiratory syndromecoronavirus (SARS-CoV) receptor, angiotensin-converting enzyme-2 (ACE2). J Biol Chem. 2005;280(34):30113-9. https://doi.org/10.1074/jbc. M505111200

19. Epelman S, Tang WH, Chen SY, Van Lente F, Francis GS, Sen S. Detection of soluble angiotensin-converting enzyme 2 in heart failure: insights into the endogenous counter-regulatory pathway of the renin-angiotensinaldosterone system. J Am Coll Cardiol. 2008;52(9):750-4. https:/ /doi.org/ 10.1016/j.jacc.2008.02.088

20. Xu J, Sriramula S, Xia H, Moreno-Walton L, Culicchia F, Domenig O, et al. Clinical Relevance and Role of Neuronal $\mathrm{AT}_{1}$ Receptors in ADAM17Mediated ACE2 Shedding in Neurogenic Hypertension. Circ Res. 2017;121(1):43-55. https: / /doi.org/10.1161/CIRCRESAHA.116.310509

21. Haga S, Yamamoto N, Nakai-Murakami C, Osawa Y, Tokunaga K, Sata T, et al. Modulation of TNF-alpha-converting enzyme by the spike protein of SARS-CoV and ACE2 induces TNF-alpha production and facilitates viral entry. Proc Natl Acad Sci U S A. 2008;105(22):7809-14. https://doi. org /10.1073/pnas.0711241105

22. Jia HP, Look DC, Tan P, Shi L, Hickey M, Gakhar L, et al. Ectodomain shedding of angiotensin converting enzyme 2 in human airway epithelia Am J Physiol Lung Cell Mol Physiol. 2009;297(1):L84-96. https:/ /doi.org/ 10.1152/ajplung.00071.2009

23. Wan Y, Shang J, Graham R, Baric RS, Li F. Receptor Recognition by the Novel Coronavirus from Wuhan: an Analysis Based on Decade-Long Structural Studies of SARS Coronavirus. J Virol. 2020;94(7). pii: e00127-20. https:/ / doi.org/10.1128/JVI.00127-20

24. Haga S, Nagata N, Okamura T, Yamamoto N, Sata T, Yamamoto N, et al. TACE antagonists blocking ACE2 shedding caused by the spike protein of SARS-CoV are candidate antiviral compounds. Antiviral Res. 2010; 85(3):551-5. https://doi.org/10.1016/j.antiviral.2009.12.001

25. Olagnier D, Scholte FE, Chiang C, Albulescu IC, Nichols C, He Z, et al. Inhibition of dengue and chikungunya virus infections by RIG-I-mediated type I interferon-independent stimulation of the innate antiviral response. J Virol. 2014;88(8):4180-94. https://doi.org/10.1128/JVI.03114-13

26. Cugola FR, Fernandes IR, Russo FB, Freitas BC, Dias JL, Guimarães KP, et al. The Brazilian Zika virus strain causes birth defects in experimental models. Nature. 2016;534(7606):267-71. https://doi.org/10.1038/nature 18296

27. Bardina SV, Bunduc P, Tripathi S, Duehr J, Frere JJ, Brown JA, et al. Enhancement of Zika virus pathogenesis by preexisting antiflavivirus immunity. Science. 2017;356(6334):175-80. https://doi.org/10.1126/science. aal4365

28. Dejnirattisai W, Supasa P, Wongwiwat W, Rouvinski A, Barba-Spaeth G, Duangchinda T, et al. Dengue virus sero-cross-reactivity drives antibodydependent enhancement of infection with zika virus. Nat Immunol. 2016;17(9):1102-8. https:/ /doi.org/10.1038/ni.3515

29. Terzian ACB, Schanoski AS, Mota MTO, da Silva RA, Estofolete CF, Colombo TE, et al. Viral Load and Cytokine Response Profile Does Not Support Antibody-Dependent Enhancement in Dengue-Primed Zika Virus-Infected Patients. Clin Infect Dis. 2017;65(8):1260-5. https://doi. org/10.1093/cid/cix558

30. Kuzmina NA, Younan P, Gilchuk P, Santos RI, Flyak AI, Ilinykh PA, et al Antibody-Dependent Enhancement of Ebola Virus Infection by Human Antibodies Isolated from Survivors. Cell Rep. 2018;24(7):1802-1815.e5. https://doi.org/10.1016/j.celrep.2018.07.035

31. Willey S, Aasa-Chapman MM, O'Farrell S, Pellegrino P, Williams I, Weiss RA, et al. Extensive complement-dependent enhancement of HIV-1 by autologous non-neutralising antibodies at early stages of infection. Retrovirology. 2011;8:16. https://doi.org/10.1186/1742-4690-8-16

32. Kuczera D, Assolini JP, Tomiotto-Pellissier F, Pavanelli WR, Silveira GF Highlights for Dengue Immunopathogenesis: Antibody-Dependent Enhancement, Cytokine Storm, and Beyond. J Interf Cytokine Res. 2018; 38(2):69-80. https://doi.org/10.1089/jir.2017.0037

33. Chen $\mathrm{Y}$, Wang $\mathrm{H}, \mathrm{Oi} \mathrm{N}, \mathrm{Wu} \mathrm{H}$, Xiong $\mathrm{W}, \mathrm{Ma} \mathrm{J}$, et al. Functions of TAM RTKs in regulating spermatogenesis and male fertility in mice. Reproduction. 2009;138(4):655-66. https:/ / doi.org/10.1530/REP-09-0101

34. The Protein Cell Atlas Webpage Available from: https://www.protein atlas.org/ENSG00000143226-FCGR2A/tissue.

35. Liu L, Wei Q, Lin Q, Fang J, Wang H, Kwok H, et al. Anti-spike IgG causes severe acute lung injury by skewing macrophage responses during acute SARS-CoV infection. JCI Insight. 2019;4(4). pii: 123158. https://doi.org/ 10.1172/jci.insight. 123158

36. Zhang L, Zhang F, Yu W, He T, Yu J, Yi CE, et al. Antibody responses against SARS coronavirus are correlated with disease outcome of infected individuals. J Med Virol. 2006;78(1):1-8. 
37. Monsalvo AC, Batalle JP, Lopez MF, Krause JC, Klemenc J, Hernandez JZ, et al. Severe pandemic 2009 H1N1 influenza disease due to pathogenic immune complexes. Nat Med. 2011;17(2):195-9. https://doi.org/10.1038/ nm.2262

38. Raj VS, Mou H, Smits SL, Dekkers DH, Müller MA, Dijkman R, et al. Dipeptidyl peptidase 4 is a functional receptor for the emerging human
coronavirus-EMC. Nature. 2013;495(7440):251-4. https://doi.org/10.1038/ nature12005

39. Wang Q, Zhang L, Kuwahara K, Li L, Liu Z, Li T, et al. Immunodominant SARS Coronavirus Epitopes in Humans Elicited both Enhancing and Neutralizing Effects on Infection in Non-human Primates. ACS Infect Dis. 2016;2(5):361-76. https://doi.org/10.1021/acsinfecdis.6b00006 